\title{
Spontaneous Delayed Hematoma at Operative Site in a Child with Anaplastic Ependymoma: A Rare Case
}

\author{
Sumit Bansal ${ }^{1}$ Ayusman Satapathy ${ }^{1}$ Suvendu Purkait ${ }^{1} \quad$ Rabi Narayan Sahu ${ }^{1}$
}

${ }^{1}$ Department of Neurosurgery, All India Institute of Medical Sciences, Bhubaneswar, Orissa, India

Indian J Neurosurg:2020;9:99-104

Intratumoral hemorrhage is a known phenomenon, especially in high-grade brain tumors. ${ }^{1}$ Delayed hematoma formation after tumor excision is rare and rarely reported. Hemorrhage into posterior fossa tumor is reported in preoperative, intraoperative, ${ }^{2}$ or postoperative period. Contributing factors may be reverse herniation due to overdraining ventriculoperitoneal shunt, high altitude flight used for travelling before tumor surgery, ${ }^{3}$ hemorrhage in residual tumor, neomembrane formation associated with dural substitute used to repair the dural defect after suboccipital craniectomy ${ }^{4}$ (fragile vessels associated with nonmembranes
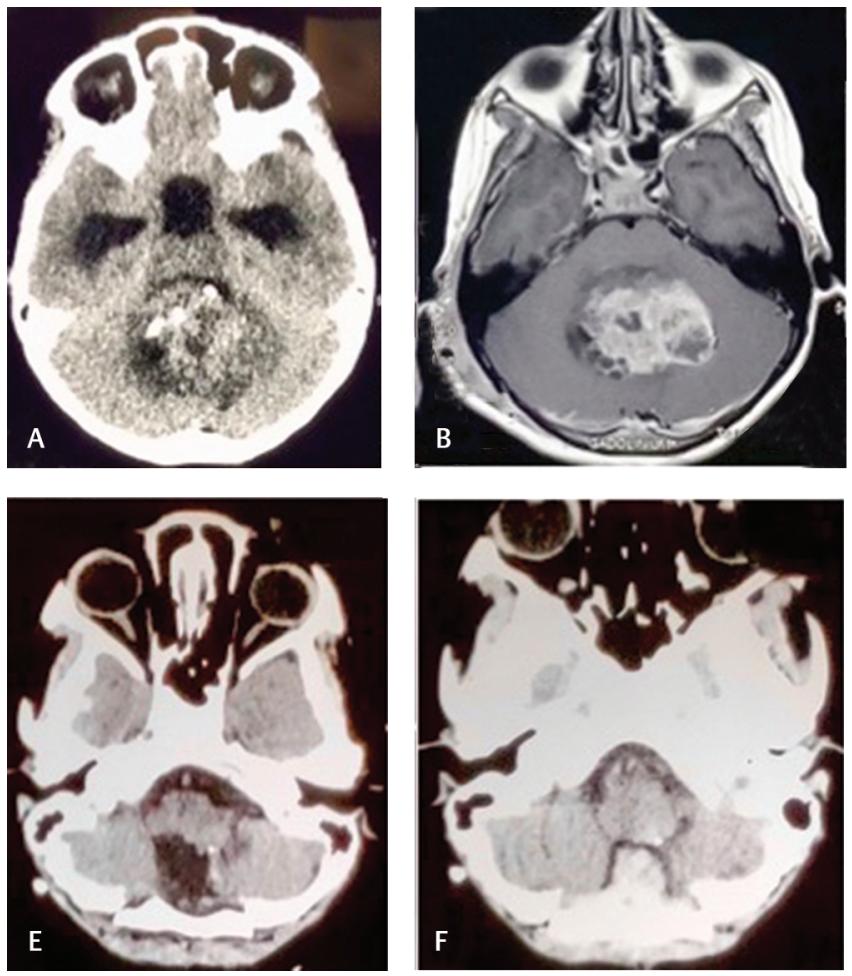

Address for correspondence Sumit Bansal, MCh, Department of Neurosurgery, All India Institute of Medical Sciences, Room No. 419, Bhubaneswar, Orissa 751019, India (e-mail: drsumitbansal@gmail.com).

have been proposed as the source of hemorrhage), or local trauma to the operative site.

Authors are reporting a rare case in which spontaneous delayed hematoma formation was present after excision of posterior fossa anaplastic ependymoma in a young child.

A 9-year-old boy was brought to our department with features of raised intra cranial pressure (ICP). Noncontrast computed tomography (NCCT) head showed midline posterior fossa tumor with hydrocephalus ( - Fig. 1A). MRI brain was suggestive of fourth ventricular tumor with heterogeneous enhancement ( - Fig. 1B-D). VP shunt followed by near total excision of tumor
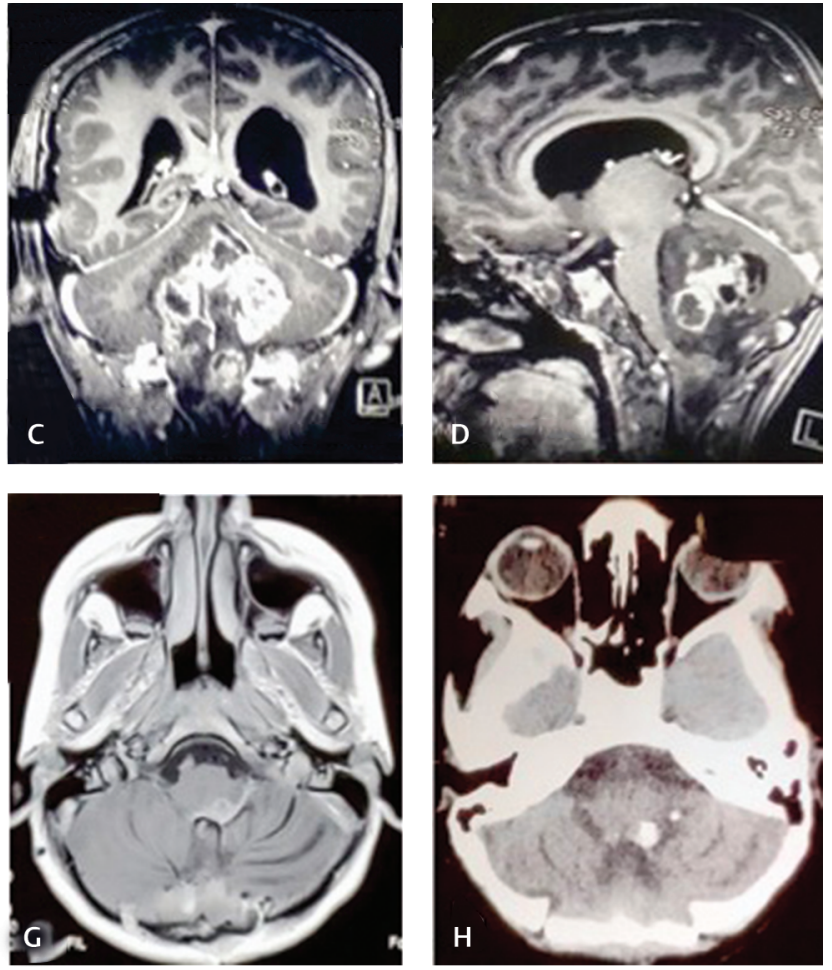

Fig. 1 (A) NCCT head showing solid cystic partially calcified midline posterior fossa tumor with upstream hydrocephalus. MRI brain (contrast) showing contrast-enhancing tumor: axial (B), coronal (C), and sagittal (D) images. Postoperative NCCT head showing good operative cavity with no hematoma (E). (F) On second admission, NCCT head showing operative cavity hematoma. (G) MRI brain (contrast) showing no residual tumor with operative site hematoma. (H) NCCT Head showing resolved posterior fossa hematoma. MRI, magnetic resonance imaging; NCCT, noncontrast computed tomography.

published online January 29, 2020
DOI https://doi.org/

$10.1055 / \mathrm{s}-0039-3401389$ ISSN 2277-954X. (c) 2021. Neurological Surgeons' Society of India.

This is an open access article published by Thieme under the terms of the Creative Commons Attribution-NonDerivative-NonCommercial-License, permitting copying and reproduction so long as the original work is given appropriate credit. Contents may not be used for commercial purposes, or adapted, remixed, transformed or built upon. (https://creativecommons.org/licenses/by-nc-nd/4.0/)

Thieme Medical and Scientific Publishers Pvt. Ltd. A-12, 2nd Floor, Sector 2, Noida-201301 UP, India 

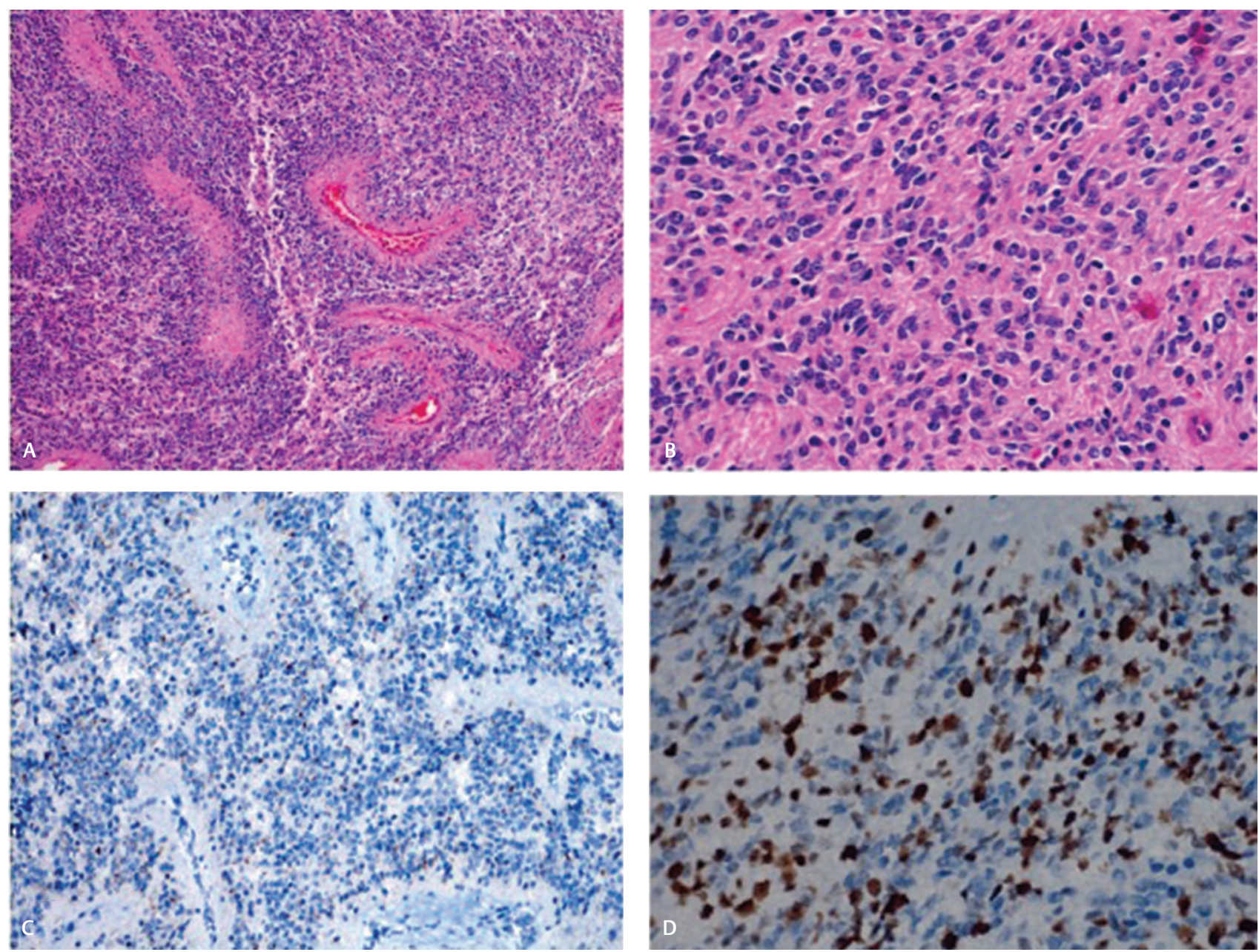

Fig. 2 (A) Tumor showing predominant pseudorosette arrangement of cells with foci of necrosis (H\&E $\times 100)$. (B) Tumor cells showing relatively uniform round to oval nuclei with granular chromatin. Frequent mitotic activity is also noted (H\&E $\times 400)$. (C) Tumor cells showing cytoplasmic dot-like immunopositivity for EMA $(\times 400)$. (D) Tumor cells showing high MIB-1 labeling index indicating high proliferative activity $(\times 400)$. EMA, epithelial membrane antigen; H\&E, hematoxylin and eosin.

was done. Tumor was greyish red, moderately vascular, firm, multilobulated, and had both solid and cystic components and firmly adhered to the floor of fourth ventricle, so a thin sheet of tumor was left attached to it. Postoperative NCCT Head was satisfactory ( - Fig. 1E). Later, patient was discharged in satisfactory condition. Histopathology was suggestive of anaplastic ependymoma, MIB-1 labeling index-30 to 35\% (WHO Grade III; -Fig. 2).

About 35 days after tumor surgery, patient came with recurrent vomiting and headache. NCCT Head showed operative site hematoma with intraventricular extension (-Fig. 1F). MRI brain with contrast showed no residual tumor with resolving hematoma at operative site ( - Fig. 1G). NCCT Head at the time of discharge showed resolved opera-

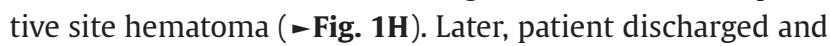
he is under regular follow-up.

In our case, delayed hematoma formation at operative site may be due to neoangiogenesis at the tumor bed because thin sheet of tumor was left behind attached to the floor of fourth ventricle. However, further studies are required to confirm our observation.

\section{Funding}

None.

\section{Conflict of Interest}

None declared.

\section{References}

1 Nutt SH, Patchell RA. Intracranial hemorrhage associated with primary and secondary tumors. Neurosurg Clin N Am 1992;3(3):591-599

2 Fukai J, Uematsu Y, Shintani A, Nakai K, Itakura T. Intraoperative hemorrhage in medulloblastoma: a case report and review of the literature. Childs Nerv Syst 2002;18(6-7):356-360

3 Mahdavi A, Baradaran N, Nejat F, El Khashab M, Monajemzadeh M. Sudden deterioration due to intra-tumoral hemorrhage of ependymoma of the fourth ventricle in a child during a flight: a case report. J Med Case Rep 2010;4:143

4 Nixon KT, Hudgins PA, Davis PC, O’Brien MS, Hudgins RJ, Hoffman JC Jr. Delayed intracranial hemorrhage in children after suboccipital craniectomy. Am J Roentgenol 1994;163(4):897-900 